\title{
Nondescent vaginal hysterectomy: can it be a better alternative to abdominal hysterectomy
}

\author{
Kavita Mahadevappa, Preeth Kanwal, Naveen Prasanna \\ Corresponding author: Dr. Naveen Prasanna, MD, DNB, FMIS; Address : Flat No: Daisy S-3, Akruti \\ Garden Apartment, Bhavani Nagar, Hubli, Karnataka, India, PIN-580023; \\ Email : prasananya10@gmail.com
}

Distributed under Attribution-Non Commercial - Share Alike 4.0 International (CC BY-NC-SA 4.0)

\begin{abstract}
Objectives: Our study aims to compare the duration of surgery, amount of blood loss, duration of stay in the hospital, intraoperative and postoperative complications in total abdominal hysterectomy (TAH) and non descent vaginal hysterectomy (NDVH). Methods: A prospective study of 100 cases with uterine size less than 12 weeks requiring hysterectomy for benign diseases were randomly selected, 50 cases underwent NDVH and 50 cases underwent TAH. The outcome was analysed by chi-square test and paired $t$ test. The $p$-value $<0.05$ was considered significant. Results: The mean duration of surgery in NDVH was lesser than TAH [52.9mins (range 25-150 mins) Vs 60.6mins (range 30-120 mins)], which was not statistically significant. However mean blood loss, drop in haemoglobin, postoperative pain, early ambulation and postoperative stay were all lesser in NDVH when compared to TAH. This was statistically significant $(\mathrm{p}<0.05)$. There were no intraoperative complications like bowel, bladder and ureteric injury in both the groups. One patient of NDVH was converted to abdominal hysterectomy due to excessive bleeding. The postoperative complications were more in TAH than NDVH. Conclusion: Our study showed NDVH is a better option than abdominal hysterectomy for uterus less than 12 weeks with lesser operative time, blood loss and hospital stay and also have lesser intraoperative and postoperative complications.
\end{abstract}

Keywords: Nondescent vaginal hysterectomy, total abdominal hysterectomy, complications, blood loss.

Hysterectomy can be performed by the abdominal, vaginal and laparoscopic route. Rate of hysterectomy has varied between 6.1 and 8.6/1000 women of all ages ${ }^{1}$. Charles Clay but made the first attempt at abdominal hysterectomy in $1843^{2}$. Since then Total abdominal hysterectomy (TAH) has been the treatment of choice for many gynaecological disorders. Reich ${ }^{3}$ et al in 1989 first reported laparoscopically assisted vaginal hysterectomy (LAVH) which has gained widespread acceptance. With the use of laparoscopy in gynaecology, minimal invasive surgery has an advantage of minimal scar, lesser blood loss and shorter duration of stay in hospital for hysterectomy. However it needs sophisticated instruments, expertise surgical team and general anaesthesia which makes it difficult to practice in limited resources, specially in rural set up. Non descent Vaginal Hysterectomy (NDVH), has been a recent alternative to laparoscopy and has advantageous of minimal invasive surgery, uterus can be removed through natural orifice. In 1934, Heaney first reported the technique of NDVH that with few modifications is probably the method that is commonly used throughout the world ${ }^{4}$. Since then there are many studies conducted to prove the

Received: $25^{\text {th }}$ April 2020, Peer review completed: $27^{\text {th }}$ May 2020, Accepted: $3^{\text {rd }}$ June 2020.

Mahadevappa K, Kanwal P, Prasanna N. Nondescent vaginal hysterectomy: can it be a better alternative to abdominal hysterectomy. The New Indian Journal of OBGYN. 2021; 7(2): 181-85. 
efficacy of NDVH. A study conducted on 80 women for NDVH by Kumar et al, had a success rate of $95 \%$ and the operating time, laparotomy conversion rate and intraoperative blood loss was directly proportional to the size of the uterus and concluded that vaginal hysterectomy is a safe and effective procedure in uteri of less than 12 weeks size $^{5}$. We are conducting a study to compare total abdominal hysterectomy (TAH) and nondescent vaginal hysterectomy (NDVH) for benign disorders of uteri of less than 12 week size.

\section{Materials and methods}

We conducted a prospective study at tertiary care hospital. Total of 100 cases admitted to the Gynaecology unit requiring hysterectomy for benign diseases were randomly selected out of which 50 cases underwent NDVH and 50 cases underwent TAH from December 2014 to May 2016.

Inclusion criteria:

1. Uterine Size $<12$ weeks

2. Mobile uterus

3. Benign conditions like Fibroid uterus/DUB/Chronic cervicitis/Adenomyosis

Exclusion criteria:

1. Prolapsed uterus

2. Genital Malignancy

3. Complex adnexal mass

4. Patients with previous major abdominal surgery or previous 2 or more LSCS

5. Vaginal stenosis

Every patient was completely evaluated by the anaesthetist and spinal anaesthesia was administered in all cases.

Main parameters were compared as follows -

1. Intraoperative blood loss - Method used: Swabs were weighed in their dry state. Then weigh the blood swabs soon after the procedure. Substract the dry weight of any unused swabs from the total dry weight. $1 \mathrm{ml}$ of blood weighs approximately $19 \mathrm{mg}$. To this value, amount of blood in the suction apparatus was added to estimate the total blood loss.

2. Time taken for surgery - This is the time duration of surgery from the time of incision till the end of the procedure. Operating time for NDVH was calculated from incision at cervicovaginal junction to the completion of closure of vault, for TAH it was calculated from incision on the abdomen to closure of skin incision.
3. Intraoperative injury - Any injury to bowel, bladder or ureter is noted.

4. Postoperative bleeding - Needing laparatomy or needing blood transfusion if any is noted.

5. Fever - This is assessed and charted 4 hourly. Fever is defined as temperature more than or equal to 38 degree celsius on 2 occasions 4 hours apart excluding the first postoperative day.

6. Pain perception - The women scored their postoperative on a $10 \mathrm{~cm}$ visual analogue scale and the results compared.

7. Wound infection - The presence of wound indurations or evidence of any frank infection if present were assessed, the patients were followed up till the date of discharge.

8. The time taken for the patient to ambulate voluntarily was noted. All patients were advised to ambulate early

9. Duration of hospital stay is noted in both groups and compared. Patients were followed up till the date of discharge.

Intraoperative and postoperative findings and complications were noted and compared in both the groups.

Statistical method: Data were analysed by "chi square test" and "t" test. P value $<0.05$ was taken as significant.

\section{Results}

In our study 100 patients underwent hysterectomy. There were 50 patients who underwent NDVH and there were 50 patients in who underwent TAH. Majority of them were in the age group of $41-50$ years. The mean age was $42.58 \pm 5.23$ years in vaginal group whereas it was $43.08 \pm 6.30$ years in abdominal group $(\mathrm{P}$ value $=0.0861)$. The mean body mass index (BMI) was $23.504 \pm 2.519 \mathrm{~kg} / \mathrm{m}^{2}$ in those who underwent NDVH and $23.104 \pm 0.0 \mathrm{~kg} / \mathrm{m}^{2}$ in those who had TAH ( $\mathrm{P}$ value $=0.149$ ). In both the groups in this study parity 3 were common, $38 \%$ in NDVH and $34 \%$ in TAH. There were 2 cases of nulliparous women undergoing TAH whereas 1 case of nulliaparous who underwent NDVH. There were 6 patients with previous scar in NDVH and 4 in TAH and the $\mathrm{p}$ value was 0.50 , which was not statistically significant. Age, BMI and parity in both the groups were comparable.

Table 1, shows indications for hysterectomy. The commonest indication for patients who underwent hysterectomy by NDVH was dysfunctional uterine bleeding (DUB) (54\%), fibroid uterus (26\%), adenomyosis (8\%), cervical polyp (2\%) respectively. Fibroid uterus $(50 \%)$ was 
The New Indian Journal of OBGYN. 2021 (January-June);7(2)

Table 1: Indications for hysterectomy

\begin{tabular}{|c|c|c|c|c|c|c|c|}
\hline \multicolumn{2}{|l|}{ Indications } & \multicolumn{2}{|c|}{ NDVH } & $\%$ & TAH & $\%$ & Total \\
\hline \multicolumn{2}{|l|}{ Adenomyosis } & \multirow{2}{*}{\multicolumn{2}{|c|}{4}} & 8.00 & 4 & 8.00 & 8 \\
\hline \multicolumn{2}{|l|}{ DUB } & \multirow{2}{*}{\multicolumn{2}{|c|}{2}} & \multirow{2}{*}{54.00} & 23 & 46.00 & 50 \\
\hline \multicolumn{2}{|c|}{ Cervical polyp } & & & & 0 & 0.00 & 1 \\
\hline \multicolumn{2}{|c|}{ Chronic cervicitis } & \multicolumn{2}{|l|}{$\begin{array}{l}1 \\
5\end{array}$} & 10.00 & 1 & 2.00 & 6 \\
\hline \multicolumn{2}{|c|}{ Fibroid } & \multicolumn{2}{|c|}{13} & 26.00 & 25 & 50.00 & 38 \\
\hline \multicolumn{2}{|l|}{ PID } & \multicolumn{2}{|c|}{0} & 0.00 & 2 & 4.00 & 2 \\
\hline \multicolumn{8}{|c|}{$\begin{array}{lrrrrr}\text { Total } & 50 & 100.00 & 50 & 100.00 & 100 \\
\end{array}$} \\
\hline \multicolumn{8}{|c|}{$\begin{array}{l}\text { DUB - Dysfunctional uterine bleeding, PID - Pelvic inflammatory disease } \\
\text { the commonest indication in TAH followed by DUB }(46 \%) \text {, } \\
\text { PID (4\%) and chronic cervicitis }(2 \%) \text {. } \\
\text { Table 2: Size of the uterus }\end{array}$} \\
\hline $\begin{array}{l}\text { Uterine size } \\
\text { (in weeks) }\end{array}$ & & & $\%$ & TA & $\%$ & Total & $\%$ \\
\hline 6 weeks & 9 & & & 4 & $8 .($ & 13 & 13.00 \\
\hline $8 \mathrm{w}$ & 15 & & & 21 & 42. & & 36.00 \\
\hline 10 weeks & 16 & & 32. & 17 & 34.00 & 33 & 33.00 \\
\hline 12 weeks & 10 & & & 8 & 16.00 & 18 & 18.00 \\
\hline Total & 50 & & 100 & 50 & 100.0 & 100 & 100.0 \\
\hline
\end{tabular}

Chi-square $=3.1762 \quad \mathrm{P}=0.3651$

Table 2, shows the uterine size in both the groups, with majority of the patients having size of 8 weeks. The size of the uteri was comparable in both the groups. Myoma screw was in 18 cases and bisection was done in 2 cases in NDVH.

Table 3, shows the intraoperative and postoperative findings of the two study groups. The mean duration of surgery in the NDVH was $52.9 \pm 26.6$ minutes (range 25150 mins) was lesser than TAH was $60.6 \pm 19.2$ mins (range 30-120mins) which was not statistically significant. However mean blood loss, drop in hemoglobin, postoperative pain, early ambulation and postoperative stay were all lesser in NDVH when compared to TAH. This was statistically

Postoperative complications were more in TAH than NDVH; however the difference was not statistically significant, as shown in Table 5. There were 2 cases of secondary hemorrhage in NDVH, one of which required laparotomy, whereas one case of TAH had secondary hemorrhage which required

Table 4: Details of blood transfusions

\begin{tabular}{cclllll}
\hline $\begin{array}{l}\text { Blood } \\
\text { transfusions } \\
\text { (numbers) }\end{array}$ & NDVH & $\%$ & TAH & $\%$ & Total & $\%$ \\
\hline 0 & 40 & 80.00 & 33 & 66.00 & 73 & 73.00 \\
1 & 8 & 16.00 & 11 & 22.00 & 19 & 19.00 \\
2 & 2 & 4.00 & 4 & 8.00 & 6 & 6.00 \\
3 & 0 & 0.00 & 2 & 4.00 & 2 & 2.00 \\
Total & 50 & 100.0 & 50 & 100.0 & 100 & 100.0 \\
\hline
\end{tabular}

Chi-square $=3.1452 ; \mathrm{P}=0.2081$

laparotomy.

\section{Discussion}

In 1990, the ACOG established some guidelines for the route of hysterectomy stating that vaginal hysterectomy is performed in women with mobile uteri, no larger than the one at 12 weeks gestation, specially if there is some uterine descent ${ }^{6}$. Abdominal hysterectomy is still the most commonly used when compared to NDVH and laparoscopic route. According to the VALUE study, by Maresh JA et al, the proportions of women having abdominal, vaginal or laparoscopically assisted hysterectomy were $67 \%, 30 \%$ and $3 \%$, respectively ${ }^{7}$. In our study with 100 patients, with

Table 3: Comparison of intraoperative and postoperative parameters in the two study groups (by t test)

\begin{tabular}{|c|c|c|c|c|c|c|}
\hline \multirow[t]{2}{*}{ Variables } & \multirow{2}{*}{$\begin{array}{l}\text { NDVH } \\
\text { Mean }\end{array}$} & \multicolumn{3}{|c|}{ TAH } & \multirow{2}{*}{ t-value } & \multirow{2}{*}{ p-value } \\
\hline & & Std.Dev & Mean & Std.Dev & & \\
\hline Duration of surgery(mins) & 52.9000 & 26.6322 & 60.6000 & 19.2099 & -1.6581 & 0.1005 \\
\hline Blood loss $(\mathrm{ml})$ & 106.4000 & 62.0240 & 205.800 & 86.1439 & -6.6214 & $0.0001 *$ \\
\hline Drop in $\mathrm{Hb}$ (in Gm \%) & 0.7680 & 0.4206 & 1.3600 & 0.5178 & -6.2746 & $0.0001 *$ \\
\hline Postoperative pain & 3.3000 & 1.0926 & 5.2000 & 1.4142 & -7.5176 & $0.0001 *$ \\
\hline Ambulation ( hours) & 10.3200 & 3.5995 & 16.3800 & 4.5306 & -7.4054 & $0.0001 *$ \\
\hline Postoperative stay (days) & 4.5600 & 2.9358 & 8.3000 & 7.7703 & -3.1838 & $0.0019 *$ \\
\hline
\end{tabular}

significant. There were no intraoperative complications like bowel, bladder and ureteric injury in both the groups. One patient of NDVH was converted to abdominal hysterectomy due to excessive bleeding.

Table 4, shows the details of blood transfusion given in both the groups. Ten patients of NDVH and 17 patients of TAH required blood transfusions, however the difference was not statistically significant.

uterine size of less than 12weeks, 50 underwent NDVH with a mean age of $42.5 \pm 5.23$ years and BMI $23.5 \mathrm{~kg} / \mathrm{m}^{2}$ and 50 underwent TAH with mean age of $43.08 \pm 6.30$ years and BMI $23 \mathrm{~kg} / \mathrm{m}^{2}$, which were comparable.

The mean duration of surgery in the NDVH group was $52.9 \pm 26.6$ minutes which was lesser than TAH group of $60.6 \pm 19.2$ mins, but this difference was not statistically significant. However mean blood loss was $106 \mathrm{ml}$ in NDVH group and $205 \mathrm{ml}$ in the TAH group and this difference was 
statistically significant. There were no intraoperative complications like bowel, bladder and ureteric injury in both the groups. Ten patients of NDVH group and 17 patients of TAH group required blood transfusions; however the difference is not statistically significant. The mean VAS score for pain in NDVH group was $3.3 \pm 1.09$ and TAH group was $5.2 \pm 1.41$, this difference was statistically significant. For NDVH group the mean postoperative ambulation time was seen at 10.3 hours and for TAH group it was 16.3 hours, which was statistically significant. In NDVH group the postoperative hospital stay was 4.5 days and that of TAH group was 8.3 days which was also statistically significant.

A total of 15 patients had postoperative complications in both the groups, out of which 6 were in the NDVH group and 9 in the TAH group, which was not statistically significant. There were 2 patients of febrile illness in NDVH group and 3 in the TAH group. There was one patient each with urinary tract infection in both the groups. There were 2 patients of wound infection in the NDVH group and 3 patients in the TAH group. There were 2 cases of secondary hemorrhage in NDVH group, one of which required laparotomy, whereas one case of TAH group had secondary hemorrhage which required re-laparotomy. One patient of NDVH group was converted to abdominal hysterectomy due to excessive bleeding.

Hemant Deshpande ${ }^{8}$ et al did a study on 100 patients with uterine size less than 12 weeks, 50 underwent TAH with a mean age 46.12 years and 50 patients underwent NDVH with a mean age of 48.74 years. The Mean duration of surgery in TAH was 75.90 minutes and 39.76 minutes in NDVH. This was statistically significant. Average intraoperative blood loss in TAH was $138.80 \mathrm{ml}$ and that of NDVH was $41.96 \mathrm{ml}$. This also was statistically significant. However there were much higher intraoperative complications in this study unlike our study. There were 4 cases of ureteric injury and one case of bowel injury in TAH and one cases of bladder injury in NDVH. The Post operatively pain scores for the patients who underwent TAH were always higher than that of NDVH and were statistically significant too. Post operative complications like febrile morbidity, wound infection, burst abdomen, wound gape, paralytic ileus were also more in TAH. TAH patients stayed for 7.14 days on an average in the hospital and NDVH patients stayed for just 3.18 days on an average. This indeed was highly significant statistically.

A total of 300 patients were included in the study done by Divya $B^{9}$ et al. One hundred and fifty patients underwent vaginal hysterectomy and 150 patients underwent abdominal hysterectomy with uterine size of less than 12 weeks. No case in the vaginal group was converted to abdominal route. There were no intraoperative complications such as bladder, rectum or urethra injuries or relaparotomies. The mean duration of surgery was 37.07 minutes in the vaginal group, whereas, it was 56.4 minutes in the abdominal group, which was statistically significant $(\mathrm{p}<0.05)$. Significantly higher blood loss of $249 \mathrm{ml}$ was noted in the abdominal hysterectomy group, compared to $102.5 \mathrm{ml}$ in the vaginal group $(\mathrm{p}<0.05)$. Postoperatively, the abdominal group required more analgesia in comparison to the vaginal group. The mean length of hospital stay was 10.87 days in the abdominal group while the duration was 4.67 days in the vaginal group.

Mean time to postoperative mobility and mean maximum postoperative body temperature in the vaginal hysterectomy group were significantly shorter and less severe respectively than those in the abdominal group $(\mathrm{p}<0.05)$. Significantly lesser number of patients required postoperative blood transfusion in the vaginal group compared to the abdominal group. Significantly high postoperative wound infection rate was noted in $33.33 \%$ of patients in the abdominal group, compared to the vaginal group. However, there was no significant difference in the rates of systemic infection like respiratory tract infection, urinary tract infection, paralytic ileus and acute gastroenteritis postoperatively in both the groups.

Nieboer et al, conducted a systematic cochrane review which included nine RCTs and concluded that vaginal hysterectomy is better in terms of intraoperative and postoperative outcomes, when compared to abdominal, laparoscopic and laparoscopic assisted vaginal hysterectomies $^{10}$. Hence, NDVH has shown lesser blood loss, lesser operative time and shorter hospital stay than abdominal hysterectomy not only in Indian studies but also in other developed and developing countries. Intraoperative and postoperative complications are also significantly less in vaginal surgeries.

\section{Conclusion}

Our study showed NDVH is a better option than abdominal hysterectomy for uterus less than 12 weeks with lesser operative time, blood loss and hospital stay and also have lesser intraoperative and postoperative complications. We must train our postgraduates in vaginal surgeries and make NDVH a popular method of hysterectomy.

\section{Conflict of interest: None. Disclaimer: Nil.}


The New Indian Journal of OBGYN. 2021 (January-June);7(2)

\section{References}

1. Stovall TG. Hysterectomy. In: Berek SJ, editor. Berek \& Novak`s Gynecology, 14th ed. Philadelphia: Lippincott Williams \& Wilkins; 2007: p.805

2. Sutton CJG. Hysterectomy: a historical perspective. In: Wood C, Maher P, eds. Bailliere's clinical obstetrics and gynaecology. $11^{\text {th }}$ ed. London: Bailliere Tindall; 1997: p. 1-23.

3. Reich H, De Caprio J, Mc Glynn F. Laparoscopic hysterectomy. J Gynaecol Surg. 1989; 5: 213-6.

4. Chandra R, Singh S. A historical review: Non descent vaginal hysterectomy. The CME committee, Agra 2004: 9-12

5. Kumar S, Antony ZK. Vaginal hysterectomy for benign non prolpased uterus-initial experience. J Obstet Gynaecol India . 2004; 54: 60-3

6. Kovac SR. Guidelines to determine the route of hysterectomy. Obstet Gynecol. 1995; 85:18-23.

7. Maresh A, Metcalfe MA, McPherson K, Overton C, Hall V, Dobbins J. The Value National Hysterectomy study: Description of the patients and their surgeries. Obstet Gynecol Survey. 2002; 57(7): 431-2.
8. Deshpande H, Burute S, Malik R. A comparative study of abdominal versus non descent vaginal hysterectomy. International Journal of Contemporary Medical Research. 2016; 3(4):1153-6.

9. Balakrishnan D, Dibyajyoti G. A Comparison between Non-Descent Vaginal Hysterectomy and Total Abdominal Hysterectomy. J Clin Diagn Res. 2016 Jan; 10(1): QC11-4. doi: 10.7860/JCDR/2016/15937.7119. Epub 2016.

10. Nieboer TE, Johnson N, Lethaby A, Tavender E, Curr E, Garry R, et al. Surgical approach to hysterectomy for benign gynaecological disease. Cochrane Database Syst Rev. 2009; (3): CD003677

\footnotetext{
Kavita Mahadevappa ${ }^{1}$, Preeth Kanwal ${ }^{2}$, Naveen Prasanna $^{3}$

${ }^{1}$ Associate Professor, KIMS, Hubli, Karnataka, India; ${ }^{2}$ Post graduate in Dept.OBG, KIMS, Hubli, Karnataka, India; ${ }^{3}$ Associate Professor, KIMS, Hubli, Karnataka, India.
} 